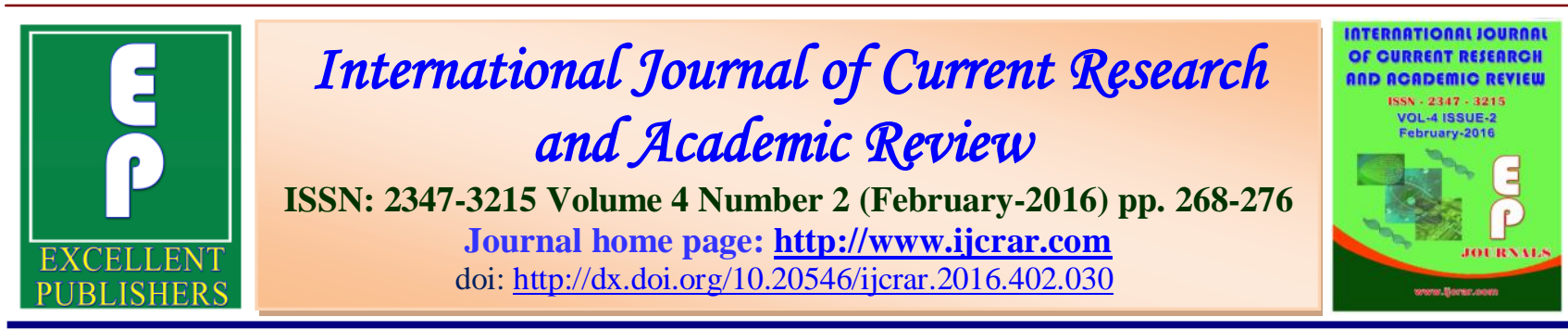

\title{
A Study on Gamma Glutamyl transferase (GGT) in Non ST Elevation Acute Coronary Syndrome (NSTE-ACS) and its correlation with Angiographic severity and cardiac events
}

\author{
V.Magesh $^{1}$, B. Sasi Kumar ${ }^{2}$ and P. Arunachalam³ \\ ${ }^{1}$ Assistant Professor, Department of Cardiology, Meenakshi Medical College and Research \\ Institute, Kanchipuram-631552, Tamil Nadu, India \\ ${ }^{2}$ Associate Professor, Department of Cardiology, Meenakshi Medical College and Research \\ Institute, Kanchipuram-631552, Tamil Nadu, India \\ ${ }^{3}$ Professor and Head, Department of Cardiology, Meenakshi Medical College and Research \\ Institute, Kanchipuram-631552, Tamil Nadu, India \\ *Corresponding author
}

\section{KEYWORDS}

Gamma Glutamyl

Transferase, Acute Coronary

Syndrome,

Non ST Elevation

Acute Coronary

Syndrome

\section{A B S T R A C T}

The purpose of this study is to investigate the diagnostic value of Gamma Glutamyl transferase (GGT) in Non ST Elevation Acute Coronary Syndrome (NSTE-ACS) and its correlation with Angiographic severity and cardiac events. Coronary Artery Disease which is one of the leading causes of mortality and morbidity all over the world, has reached epidemic proportions worldwide recently in both Developed as well as Developing Countries. Coronary artery disease causes approximately $9.4 \%$ of total deaths in less developed countries and $16.3 \%$ of all deaths in well developed countries. Non ST Elevation Acute Coronary Syndrome and its Angiographic severity and cardiac events was studied in three groups depends on ACS Significant Stenosis and ACS non significant stenosis. In all three groups, the levels of Gamma Glutamyl Transferase enzyme in Non ST Elevation Acute Coronary Syndrome patients (both Unstable AnginaUA and NonST Elevation Myocardial Infarction NSTEMI) who were undergoing coronary angiogram and Control population of effort angina patients with normal coronary arteries by evaluation of atherosclerotic load. The serum levels of Median GGT values were significantly elevated in ACS patients with significant angiographic stenosis is in comparison with ACS without significant stenosis Serum GGT is an easily available, cost effective and simple biomarker marker, its routine measurement on admission may be helpful for identification of high-risk patients in clinical practice.

\section{Introduction}

Acute Coronary Syndrome (ACS) is a major part of chronic inflammatory athroscleotic coronary artery disease and it has evolved as a broad term that refers to spectrum of conditions compatible with acute myocardial ischemia and/or infarction that are usually due to sudden reduction in coronary blood supply ${ }^{1}$. The CREATE $^{2}$ registry has shown 
that our country has the highest burden of ACS in the world. The absence of persistent ST-elevation is suggestive of NSTE- ACS. (except true posterior wall myocardial infarction ) and it has been subdivided on the basis of cardiac biomarkers of myocyte damage (eg, CPK - MB, cardiac Troponin,) in to Unstable Angina and Non ST Elevation Myocardial Infarction (NSTEMI) in appropriate clinical conditions ${ }^{1}$. If cardiac biomarkers are elevated, the patient is diagnosed as NSTEMI ${ }^{3}$. Otherwise, the patient is considered to have Unstable Angina( UA). ST depression, transient STelevation, and /or prominent $\mathrm{T}$-wave inversions may be present but are not must for diagnosis of NSTEMI. Abnormalities on the ECG and elevated troponins alone are not enough to diagnose the ACS but must be interpreted in the appropriate clinical scenario. Thus, UA and NSTEMI are closely related clinical scenarios whose pathogenetic mechanisms and clinical presentations are similar but vary in severity.

Gamma-glutamyl transferase (GGT) is an important enzyme found to be responsible for the extracellular catabolism of Glutathione $^{4}$ and has a unique role in oxidation of LDL cholesterol in the evolving atherosclerotic plaque and gradual progression of atherosclerosis in coronary $\operatorname{arteries}^{5}$.

Epidemiologic studies have also reported that serum GGT levels have predictive and prognostic value for cardiovascular disease and mortality in the general population.

Similarly, GGT activity also has been demonstrated recently to be an independent risk factor for myocardial infarction (MI) and cardiac death in patients with documented coronary artery disease. The evaluation of the levels of low cost, easily available GGT in patients with NSTE-ACS, can be helpful for for investigating the association of GGT and coronary angiographic severity,major cardiac events as well as risk stratification \& prognosis assessment in these group of patients

\section{Materials and Methods}

\section{Chemicals}

GGT kits were purchased from immune Diagnostic kits, USA and All the other chemicals used were of analytical grade.

\section{Experimental Design}

108 patients in the age group of $31-70$ admitted in the intensive care unit of Meenakshi Medical College Hospital And Research Institute, Kanchipuram, Tamil Nadu, India for the study. This includes 75 male patients and 33 female patients with ACS significant stenosis and ACS non significant stenosis. The patients were divided into three groups are included,

Group- I - Control (Normal subjects)

Group-II - Acute chronic syndrome significant stenosis

Group-III- Acute chronic syndrome non significant stenosis

\section{Ethical Concern}

Ethical clearance was obtained from the Ethical committee meeting conducted at Meenakshi Medical College and Hospital.

\section{Biochemical analysis}

The activity of $\gamma$-glutamyl transferase was estimated according to the method of Orlowski and Meister (1965) modified by Rosalki and Rao (1972) 


\section{Cardiogram analysis}

A 12 lead Electrocardiogram and Complete Echocardiogram including Doppler examination was performed.

\section{Results andDiscussion}

\section{Gamma Glutamyl Transferase (GGT) In} Acute Coronary Syndrome

In all three groups, median serum of GGT levels were significantly decreased in control groups when compared with Acute coronary syndrome groups. In our study shows the median of Gamma Glutamyl Transferase enzyme values were significantly elevated in NSTE - Acute coronary syndrome $(\mathrm{p}<0.0045) \quad$ when compared with control polulation. The Median GGT values were significantly elevated in ACS significant angiographic stenosis $(\mathrm{p}<0.001)$ compared with ACS with insignificant angiographic stenosis.

Table.1 shows the variation in median serum level of GGT during the study in the three different groups.

\begin{tabular}{|l|l|l|l|l|l|l|}
\hline $\begin{array}{l}\text { Gamma } \\
\text { Glutamyl } \\
\text { transpeptidase } \\
\text { (U/L) }\end{array}$ & $\begin{array}{l}\text { ACS } \\
\text { significant } \\
\text { Stenosis }\end{array}$ & $\%$ & $\begin{array}{l}\text { ACS Non } \\
\text { Significant } \\
\text { Stenosis }\end{array}$ & $\%$ & Control & $\%$ \\
\hline$<25$ & 1 & 1.28 & 28 & 93.33 & 45 & 100.00 \\
\hline $26-35$ & 27 & 34.62 & 2 & 6.67 & 0 & 0.00 \\
\hline$>35$ & 50 & 64.10 & 0 & 0.00 & 0 & 0.00 \\
\hline Total & 78 & 100.00 & 30 & 100.00 & 45 & 100.00 \\
\hline
\end{tabular}

\begin{tabular}{|l|l|l|l|l|}
\hline Groups & Count & Sum & Average & Variance \\
\hline $\begin{array}{l}\text { ACS Significant } \\
\text { Stenosis }\end{array}$ & 78 & 2991 & 38.34615 & 47.86563 \\
\hline $\begin{array}{l}\text { ACS Non } \\
\text { Significant } \\
\text { Stenosis }\end{array}$ & 30 & 586 & 19.53333 & 14.74023 \\
\hline Control & 45 & 688 & 15.28889 & 9.528283 \\
\hline
\end{tabular}

ANOVA

\begin{tabular}{|l|l|l|l|l|l|l|}
\hline $\begin{array}{l}\text { Source of } \\
\text { variation }\end{array}$ & SS & Df & MS & F & P-Value & F-crit \\
\hline $\begin{array}{l}\text { Between } \\
\text { Groups }\end{array}$ & 17768.28 & 2 & 8884.138 & 294.02 & 0.0045 & 3.056 \\
\hline $\begin{array}{l}\text { Within } \\
\text { Groups }\end{array}$ & 4532.365 & 150 & 30.21577 & & & \\
\hline Total & 22300.64 & 152 & & & & \\
\hline
\end{tabular}




\section{Gamma Glutamyl Transferase (GGT) and vessel grades}

Table 2: Shows the variation in median serum levels of GGT during the study in three different vessel disease condition. In our study, median serum GGT levels were significantly $(p<0.001)$ decreased in control groups when compared with single vessel disease, double vessel disease and triple vessel disease condition.

\begin{tabular}{|c|c|c|c|c|}
\hline $\begin{array}{l}\text { GGT levels Vs } \\
\text { Vessel Grades }\end{array}$ & Normal & SVD & DVD & TVD \\
\hline$<25$ & 28 & 1 & 0 & 0 \\
\hline $26-35$ & 2 & 24 & 3 & 0 \\
\hline$>35$ & 0 & 12 & 17 & 21 \\
\hline Total & 30 & 37 & 20 & 21 \\
\hline $\begin{array}{l}\text { GGT levels Vs } \\
\text { Vessel Grades }\end{array}$ & Count & Sum & Average & Variance \\
\hline Normal & 30 & 586 & 19.53 & 14.74023 \\
\hline SVD & 37 & 1255 & 33.9189 & 41.68769 \\
\hline DVD & 20 & 822 & 41.1 & 27.46316 \\
\hline TVD & 21 & 914 & 43.52381 & \begin{tabular}{|l|}
11.1619 \\
\end{tabular} \\
\hline
\end{tabular}

ANOVA

\begin{tabular}{|l|l|l|l|l|l|l|}
\hline $\begin{array}{l}\text { Source of } \\
\text { Variation }\end{array}$ & Ss & df & MS & F & P-value & F-crit \\
\hline $\begin{array}{l}\text { Between } \\
\text { groups }\end{array}$ & 9108.174 & 3 & 3036.058 & 118.14 & 0.0001 & 2.691979 \\
\hline $\begin{array}{l}\text { Within } \\
\text { Groups }\end{array}$ & 2673.262 & 104 & 25.70 & & & \\
\hline Total & 11781.44 & 107 & & & & \\
\hline
\end{tabular}

Gamma Glutamyl Transferase (GGT) And Gensini Scores

Table 3: Shows the variation in median serum levels of GGT during the study in three different Gensini scores. The gensini score ranges were $51-100,26-50,<25$ in people who where having GGT values >35, 26-35, <25 U/l respectively. In our study, median serum GGT levels were significantly $(\mathrm{p}<0.001)$ increased in 26-50, 51-100 gensini scores when compared below 25 gensini scores.

\begin{tabular}{|l|l|l|l|l|}
\hline $\begin{array}{l}\text { GGT levels Vs } \\
\text { Gensini }\end{array}$ & $<25$ & $26-50$ & $51-100$ \\
\hline$<25$ & 1 & 17 & 8 \\
\hline $26-35$ & 0 & 8 & 13 \\
\hline$>35$ & 1 & 27 & 50 \\
\hline
\end{tabular}


Int.J.Curr.Res.Aca.Rev.2016; 4(2): 268-276

\begin{tabular}{|l|l|l|l|l|}
\hline $\begin{array}{l}\text { GGT levels Vs } \\
\text { Gensini }\end{array}$ & Count & Sum & Average & Variance \\
\hline$<25$ & 1 & 12 & 12 & 0 \\
\hline $26-50$ & 27 & 682 & 25.25926 & 426.7373 \\
\hline $51-100$ & 50 & 2919 & 58.38 & 768.3629 \\
\hline
\end{tabular}

ANOVA

\begin{tabular}{|l|l|l|l|l|l|l|}
\hline $\begin{array}{l}\text { Source of } \\
\text { variation }\end{array}$ & SS & df & MS & F & P-value & F-crit \\
\hline $\begin{array}{l}\text { Between } \\
\text { Groups }\end{array}$ & 20426.02 & 2 & 10213.01 & 15.71395 & 0.002 & 3.118642 \\
\hline $\begin{array}{l}\text { Within } \\
\text { Groups }\end{array}$ & 48744.97 & 75 & 649.9329 & & & \\
\hline Total & 69170.99 & 77 & & & & \\
\hline
\end{tabular}

Gamma Glutamyl Transferase (GGT) And Adverse Events

Table.5 showed intra hospital outcomes for NSTE-ACS, as more number of adverse events (total of 18 events-Cardiogenic shock 3, arrhythmias 6, Heart failure 6 and Death 1) in significant stenosis subgroup in contrast to 2 events (arrhythmia 1, heart failure 1) in non significant angiographic stenosis subgroup. Mean GGT values were above $43 \mathrm{U} / 1$ in adverse events subgroup. $\mathrm{P}$ value was insignificant 0.81

\begin{tabular}{|l|r|r|r|r|}
\hline $\begin{array}{l}\text { Adverse } \\
\text { Events }\end{array}$ & \multicolumn{2}{|c|}{ ACS Signicant Stenosis } & \multicolumn{2}{c|}{ ACS Non significant Stenosis } \\
\hline & count & mean GGT Levels (U/L) & count & mean GGT Levels (U/L) \\
\hline $\begin{array}{l}\text { Cardiac } \\
\text { Shock }\end{array}$ & 3 & 44.67 & 0 & 0 \\
\hline Arrhythmia & 6 & 44.33 & 1 & 20 \\
\hline Heart failure & 6 & 43.67 & 1 & 22 \\
\hline Death & 3 & 44.67 & 0 & 0 \\
\hline \multicolumn{2}{|l|}{ Chi Square Statistic } & 0.952 & & \\
\hline \multicolumn{2}{|c|}{ Degree of Freedom } & 3 & & \\
\hline \multicolumn{2}{|c|}{ P value } & 0.813 & & \\
\hline
\end{tabular}

Gamma Glutamyl Transferase (GGT) in acute coronary syndrome

In our study median Gamma Glutamyl Transferase enzyme GGT values were significantly elevated in NSTE - Acute coronary syndrome around $33.12 \mathrm{U} / 1$ vs control polulation around 15.3 U/l. (P Value 0.0045).
Median GGT values were significantly elevated in ACS significant angiographic stenosis of around $38.34 \mathrm{U} / 1$ in in comparison to $19.5 \mathrm{U} / \mathrm{l}$ in ACS with insignificant angiographic stenosis, $\mathrm{P}$ value 0.001 .

In the present study the mean GGT levels were elevated in patients with NSTE-ACS 
population than controls which was also correlating with degree of stenosis of caoronary arteries, left ventricular EF, Trop $\mathrm{T}$ and CPK-MB. These findings can be explained by means of GGT-mediated reactions influencing plaque evolution and rupture ${ }^{5}$.

The present study concurs with study findings of Dogan et $\mathrm{al}^{5}$ which found median GGT 32U/l in ACS vs 16U/1 in effort angina group of patient and median GGT of 37 in significant stenosis subset versus $22 \mathrm{U} / 1$ insignificant stenosis subset on NSTE-Acute Coronary Syndrome population.our study finding are also supported by study by Emiroglu ${ }^{6}$ et al, Demircan et $\mathrm{al}^{7}$ and Ulus et $\mathrm{al}^{8}$. The Non ST elvation ACS occurs due to the disruption or erosion of the vulnerable plaques $^{9}$, usually associated with subtotal occlusion of the culprit arteries. These plaques include a big lipid core, also increased inflammatory activity, and a thin fibrous cap. There is clear evidence that atherosclerotic plaques contain increased GGT activity ${ }^{10,11}$ and GGT oxidizes LDL cholesterol within the coronary plaques in the presence of Fe ions.

Therefore, GGT can trigger the vulnerability and evolution of the plaques in ACS evolution This findings have been supported by many large epidemiologic studies 5 .

Our study has found such an elevation of GGTP, with more prominent elevation in NSTEMI patients GGTP was independently related to NSTE-ACS, as well as hypertension, smoking, and reduction of left ventricular EF. It is well-known that abundance of cardiovascular risk factors and low EF increase the likelihood of UAP\&NSTEMI and risk of adverse cardiac events in patients presenting with chest pain.

\section{Gamma Glutamyl Transferase (GGT) AND Vessel Grades}

Our study examined the level of serum GGT in patients with NST-ACS ACS to estimate the load of atherosclerosis. Our findings indicate that high levels of GGT were associated with increased load of atherosclerosis in patients with ACS.

The angiographic findings in NSTE - ACS patient group were Single vessel disese of $47.5 \%$, Double vessel disease of $25 \%$ and triple vessel disease of $27.5 \%$ ( $\mathrm{P}$ value $0.000)$ Left main disease was found in 6.5 $\%$ of significant stenosis subgroup. ( $\mathrm{P}$ value 0.15). Our study also found that median GGT greater than $30 \mathrm{U} / 1$ was useful for identifying the NSTE-ACS patients with significant stenosis, with a sensitivity and specificity of above $85 \%$.

\section{Gamma Glutamyl Transferase (GGT) and Gensini Scores}

In our study, median serum GGT levels were significantly $(\mathrm{p}<0.001)$ increased in 26-50, 51-100 gensini scores when compared below 25 gensini scores. Our findings and GGT \& Gensini correlation were also similar to Açikel et al73 study which found a significant relationship between serum GGTP levels and CAD extent and severity assessed by Gensini scoring in patients who underwent coronary angiography study for atherosclerosis burden evaluation with fatty liver correlation study

Recently Baktir AO et al ${ }^{12}$ have evaluated GGTP activity and the CAD burden by SYNTAX score correlation in patients with STEMI. Although they found significant positive association between SYNTAX score and major adverse cardiac events, the study has failed to show any correlation 
Int.J.Curr.Res.Aca.Rev.2016; 4(2): 268-276

between serum GGT levels and Coronary lesion lesion complexity and severity by SYNTAX scores.

\section{Gamma Glutamyl Transferase (GGT) And Adverse Events}

In our study where we followed for intra hospital outcome evaluation for NSTE-ACS, the results were more number of adverse events (total of 18 events-Cardiogenic shock 3 , arrhythmias 6, Heart failure 6 and Death 1) in significant stenosis subgroup in contrast to 2 events (arrhythmia 1, heart failure 1) in non significant angiographic stenosis subgroup.

The present study also correlates with recently conducted study in which over 600 ST Elevation Myocarial Infarction patients who were undergoing primary PCI were evaluated by Gul et $\mathrm{al}^{13}$ for correlation of serum GGTP on admission and in hospital cardiovascular adverse events and mortality. They found that patients who were having high serum GGT more than 37 had higher risk of mortality and adverse cardiovascular events.

The present study also supported by GGT and major adverse cardiac events MACE studies done by Dogan et $\mathrm{al}^{5}$, Apkek et $\mathrm{al}^{14}$, Gul et $\mathrm{al}^{13}$ and Lazzeri et $\mathrm{al}^{15}$ in various groups of ACS.

Elevated serum GGTP level is an independent $\mathrm{CV}$ risk factor which predicts $\mathrm{CV}$ events, non-fatal Myocardial Infarction and mortality due to cardiac cause in unselected populations, in patients with history of MI, and in patients with ACS after adjusting for other CAD risk factors

In CAD population, serum GGT was associated with prognosis prediction independent of a variety of other established traditional risk markers. Even though the mechanisms linking GGTP and CV mortality have not yet been clearly demonstrated, various studies suggested that high GGTP levels were associated with high atherosclerosis burden which may explain the poor $\mathrm{CV}$ outcomes.

\section{Statistical analysis}

For statistical analysis, one way analysis of analysis of Variance (ANOVA) was used, followed by the Newman-Keuls Multiple Comparison test.

\section{Conclusion}

From the present study, to conclude, GGT levels can be increased in patients with NSTEACS, especially in Non STEMI, and identify those with significant coronary angiographic stenosis. Moreover, its relatively high levels can increase the risk of adverse cardiac events like cardiovascular events, non-fatal MI, and cardiac mortality in such patients 43-52. Thus, its measurement may be useful for prognostic evaluation of patients with NSTE-ACS independent of other established risk markers. As serum GGT is an easily available, cost effective and simple biomarker marker, its routine measurement on admission may be helpful for identification of high-risk patients in clinical practice.

\section{References}

1.Amsterdam EA, Wenger NK, Brindis RG, Casey DE Jr, Ganiats TG, Holmes DR Jr, Jaffe AS, Jneid H, Kelly RF, Kontos MC, Levine GN, Liebson PR, Mukherjee D, Peterson ED, Sabatine MS, Smalling RW, Zieman SJ. 2014 ACC/AHA guideline for the management of patients with non-ST-elevation acute 
coronary syndromes: a report of the American College of Cardiology/ American Heart Association Task Force on Practice Guidelines. Circulation. 2014;130:e344-e426

2.Gupta R. Recent trends in coronary heart disease epidemiology in India. Indian Heart J. $2008 \quad$ MarApr; 60 (2 Suppl B):B4-18

3.Newby LK, Jesse RL, Babb JD, et al. ACCF 2012 expert consensus document on practical clinical considerations in the interpretation of troponin elevations: a report of the American College of Cardiology Foundation Task Force on Clinical Expert Consensus Documents. J Am Coll Cardiol. 2012;60:2427-63

4.Mason JE, Starke RD, Van Kirk JE. Gamma-glutamyl transferase: a novel cardiovascular risk biomarker. Prev Cardiol 2010; 13:36-41.

5.Dogan A, Icli A, Aksoy F, et al. Gammaglutamyltransferase in acute coronary syndrome patients without ST elevation and its association with stenotic lesion and cardiac events. Coron Artery Dis 2012; 23:39-44. 2009; 136:80-5

6.Emiroglu MY, Esen OB, Bulut M, Karapinar H, Kaya Z, Akcakoyun M, et al. GGT levels in type II diabetic patients with acute coronary syndrome (does diabetes have any effect on GGT levels in acute coronary syndrome). Acta Diabetol 2010. doi: $\quad$ 10.1007/s00592-010-0208-2.

7.Demircan S, Yazici M, Durna K, Kilicaslan F, Demir S, Pinar M, Gulel O. The importance of gamma-glutamyltransferase activity in patients with coronary artery disease. Clin Cardiol 2009; 32:220225.
8.Ulus T, Yildirir A, Sade LE, Temiz A, Polat E, Bozbas, H, et al. Serum gammaglutamyl transferase activity: new high-risk criteria in acute coronary syndrome patients? Coron Artery Dis 2008; 19:489-495

9.Bassand JP, Hamm CW, Ardissino D, Boersma E, Budaj A, Ferna ndezAvile'sF,et al. Guidelines for the diagnosis and treatment of non-STsegment elevation acute coronary syndromes. Eur Heart J 2007; 28:1598- 1660.

10.Paolicchi A, Emdin M, Ghliozeni E, Ciancia E, Passino C, Popoff G, Pompella A. Atherosclerotic plaques contain gamma-glutamyl transpeptidase activity. Circulation 2004; 109:1140.

11.Franzini M, Corti A, Martinelli B, Del Corso A, Emdin M, Parenti GF, et al. Gamma-glutamyltransferase activity in human atherosclerotic plaquesbiochemical similarities with the circulating enzyme. Atherosclerosis 2009; 202:119-127

12.Baktir AO1, Sarli B2, Demirci E2, Saglam H2, Kurtul S2, Sahin O2, Demirbas M2, Arinc H. $\gamma$-Glutamyl Transferase Activity and the Burden of coronary Atherosclerosis in Patients With ST-Segment Elevation Myocardial Infarction. Angiology. 2014 Oct;65(9):812-6

13. Gul M, Uyarel H, Ergelen M, Ekmekci A, Ozal E, Murat A, Kul S, Celik O, Karaca G, Akturk F, Eksik A., The relationship between $\gamma$ glutamyl transferase levels and the clinical outcomes in patients with ST-segment elevation myocardial infarction undergoing primary percutaneous coronary intervention. Coron Artery Dis. 2013 Jun; 24(4): 272-8. 
Int.J.Curr.Res.Aca.Rev.2016; 4(2): 268-276

14.Enbiya Aksakala, Ibrahim Halil Tanbogab, Mustafa Kurtb, Mehmet Ali Kaygınb, Ahmet Kayab, The relation of serum gammaglutamyl transferase levels with coronary lesion complexity and longterm outcome in patients with stable coronary artery disease. Athero-sclerosis. Volume
221, Issue 2, April 2012, Pages 596601

15.Breitling LP, Grandi NC, Hahmann H, et al. Gamma glutamyltransferase and prognosis in patients with stable coronary heart disease followed over 8years. Atherosclerosis. 2010. 210:649-55.

\section{How to cite this article:}

Magesh, V., B. Sasi Kumar and Arunachalam, P. 2016. A Study on Gamma Glutamyl transferase (GGT) in Non ST Elevation Acute Coronary Syndrome (NSTE-ACS) and its correlation with Angiographic severity and cardiac events. Int.J.Curr.Res.Aca.Rev. 2016.4(2): 268-276. doi: http://dx.doi.org/10.20546/ijcrar.2016.402.030 